\title{
PENN Neurodegenerative Disease Research - In the Spirit of Benjamin Franklin
}

\author{
John Q. Trojanowski \\ Institute on Aging, Center for Neurodegenerative Disease Research, Alzheimer Disease Core Center, Udall \\ Parkinson's Research Center, Department of Pathology and Laboratory Medicine, University of Pennsylvania \\ School of Medicine, Philadelphia, Pa., USA
}

\section{Key Words}

Aging • Alzheimer's disease • Parkinson's disease •

Amyotrophic lateral sclerosis $\cdot$ Neurodegenerative disease $\cdot$ Frontotemporal dementia

\begin{abstract}
Benjamin Franklin (1706-1790) was entrepreneur, statesman, supporter of the public good as well as inventor, and his most significant invention was the University of Pennsylvania (PENN). Franklin outlined his plans for a college providing practical and classical instruction to prepare youth for real-world pursuits in his 'Proposals Relating to the Education of Youth in Pensilvania' (1749), and Franklin's spirit of learning to serve society guides PENN to the present day. This is evidenced by the series of articles in this special issue of Neurosignals, describing research conducted by seasoned and newly recruited PENN faculty, addressing consequences of the longevity revolution which defines our epoch at the dawn of this millennium. While aging affects all organ systems, the nervous system is most critical to successful aging. Thus, the articles in this special issue of Neurosignals focus on research at PENN that is designed to prevent or ameliorate aging-related neurodegenerative disorders such as Alzheimer's and Parkinson's disease, amyotrophic lateral
\end{abstract}

sclerosis and frontotemporal dementia. This research could enhance our chances of aging successfully in the continuing longevity revolution, and the essay here provides context and background on this research.

Copyright $\odot 2008$ S. Karger AG, Basel

\section{Introduction}

The United States, like many countries, is experiencing a seismic shift in its demographics due to 2 rapidly growing segments of the population: the 'oldest old', $>85$ years of age, and the 'baby boomers' born between 1946 and 1964 [1,2]. It is estimated that between 2000 and 2030 this older population will double and that by 2050 there will be 5 times the number of those aged 85 and older compared to the year 2000 [3]. This rapid growth is due in large part to astonishing increases in life expectancy in the last millennium. For example, estimates suggest that life expectancy increased $\sim 27$ years in less than a century from 1900 to 1990, while an increase of about the same number of years occurred in the nearly 5 centuries extending from the Bronze Age to about 1900 [4]. Currently, a 65-year-old man can anticipate living approximately 18 additional years, while an 85-year-old woman

\section{KARGER}

Fax +4161306 1234 E-Mail karger@karger.ch www.karger.com
(C) 2008 S. Karger AG, Basel

1424-862X/08/0161-0005\$24.50/0

Accessible online at:

www.karger.com/nsg
John Q. Trojanowski, MD, PhD, Institute on Aging and Center for

Neurodegenerative Disease Research, University of Pennsylvania School of Medicine HUP, Maloney 3rd Floor, Department of Pathology and Laboratory Medicine 36th and Spruce Streets, Philadelphia, PA 19104-4283 (USA)

Tel. +1 215662 6399, Fax +1 215349 5909, E-Mail trojanow@mail.med.upenn.edu 


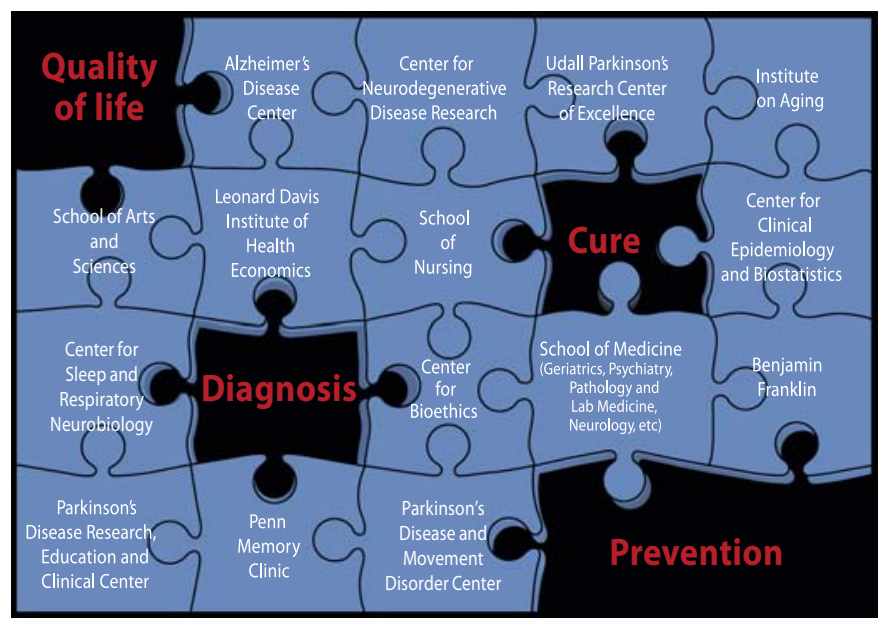

Fig. 1. PENN neurodegenerative disease research - solving the puzzle! This figure schematically illustrates how the synergistic collaborations among the investigators and programs mentioned in this essay converge to find better diagnostics, cures and preventions for aging-related neurodegenerative diseases in order to achieve the shared goal of improving the quality of life for the millions of individuals who are now, or will in the future, be affected by these disorders.

can look forward to living about 7 more years, and an 85year-old man will have 6 additional years [3].

The good news about this longevity revolution is that Americans are not only living longer now, but disability rates in the United States continue to decline from the 1980s to the present [5]. The changes to date have been dramatic, but even greater transformations will occur in society as the baby boomers enter their 7 th decade of life and live well beyond their ancestors to the 9 th decade or even longer. Indeed, starting in 2006, the leading edge of $\sim 77$ million American baby boomers began turning 60! However, the longevity revolution is not all good news, since, if action is not taken now to plan for this demographic 'sea change', aging-related disorders like Alzheimer's disease $(\mathrm{AD})$ may have ominous consequences. In this regard, $\mathrm{AD}$ and related disorders provide an excellent example of the deleterious repercussions of societal inaction. For example, in 2000, there were about 4.5 million $\mathrm{AD}$ patients in the United States. Yet, since the prevalence of $\mathrm{AD}$ is highest in individuals who are $\geq 85$ years old, by 2050, the number of Americans with AD is expected to reach $>13$ million if nothing is done very soon to delay or prevent the onset of AD [6]. Significantly, the costs to Medicare for treating AD patients were estimated to be about USD 62 billion in 2000. But, Medicare costs will increase to $\sim$ USD 1 trillion by 2050 for treating ben- eficiaries with $\mathrm{AD}$ and related dementias if no effective treatments or preventions are developed [7-9]. Hence, if demography is the history of the future written now, then the future solvency of Medicare is in jeopardy, yet it is important to emphasize that the future is malleable and that it can be changed now. Indeed, models of the future incidence and prevalence of $\mathrm{AD}$ predict that if the onset of $\mathrm{AD}$ is delayed by just 1 year, this will reduce the number of AD patients by $\sim 800,000$ over the next 5 decades, while an intervention that delays the onset of AD by 5 years will reduce the incidence of $\mathrm{AD}$ by $50 \%$, thereby cutting the costs of this devastating dementia by half [8].

Thus, preventative and ameliorative strategies will be crucial to avoid the potential detrimental consequences of the current dramatic shift in demographics, and evidence suggests that delaying the onset of AD may well be within our reach. For example, reviews of factors associated with the risk of developing dementia suggest there may be life styles and activities that show potential as preventative strategies for dementia, but more research is needed to elucidate the determinants of successful aging and preventative strategies to reduce aging-related functional limitations [10, 11]. Further, intensified efforts also are needed to develop effective disease-modifying therapies for $\mathrm{AD}$ and other aging-related neurodegenerative diseases. To follow are highlights of efforts at the University of Pennsylvania (PENN) to achieve these goals.

\section{PENN Research Programs on Aging-Related Neurodegenerative Diseases}

The long predicted 'age boom' is upon us, but we as a society are totally unprepared to manage it from medical, public health, education and fiscal perspectives. PENN has made a significant commitment to address this public health issue through research programs that focus on aging and aging-related brain diseases, and several of these programs (but by no means all of them at PENN) are briefly highlighted here. These programs reflect efforts at PENN to fit the pieces of the neurodegenerative disease puzzle together so that we are able to understand the mechanisms that underlie them and thereby develop better ways to diagnose, treat and, perhaps, even prevent neurodegenerative diseases, therefore improving the quality of life for all members of our aging populations (fig. 1). More details on recent progress from these research programs are provided in the 11 reviews by PENN faculty that follow this overview. 
For example, the PENN Institute on Aging (IOA), which was founded more than 25 years ago by Vincent Cristofalo, is dedicated to improving the health and wellbeing of our aging population through the efforts of approximately 200 IOA fellows in highly collaborative programs on aging research, education and clinical care (http://www.med.upenn.edu/aging). The IOA is currently directed by John Q. Trojanowski, and PENN is among the top 10 National Institute on Aging (NIA) funded institutions. PENN faculty/IOA fellows lead many aging-focused grants funded by the NIA and other components of the National Institutes of Health (NIH), the Commonwealth of Pennsylvania, industry, private foundations and other sources. While the IOA is centered in the PENN School of Medicine, it seeks to have an impact across the PENN campus and beyond. Thus, Kathy Jedrziewski, the Deputy Director of the IOA, recently worked for the past 2 years with the Alzheimer's Association, the Center for Disease Control and experts from around the Nation to formulate 'The Healthy Brain Initiative', which is a remarkable 'roadmap' for the public on how to maintain cognitive health throughout the life span (for details, see www.cdc.gov/aging and www.alz. org). Moreover, the IOA Pilot Grant Award Program stimulates new aging research and educational initiatives among PENN faculty by supporting 8 new pilot initiatives per year, for up to USD 50,000 per grant. These IOA Pilot Grants are made possible by funding from a private foundation and PENN School of Medicine resources. Preference for pilot awards is given to junior faculty who seek to obtain pilot data to launch new initiatives that clearly have a high likelihood of garnering sustained extramural support from the NIA, NIH or other external funding agencies.

The Center for Neurodegenerative Disease Research (CNDR), directed by Virginia M.-Y. Lee, was founded in 1991 and is closely allied with the IOA by also functioning as a 'center without walls' wherein PENN investigators collaborate in the study of neurodegenerative diseases (http://www.uphs.upenn.edu/cndr/). The mission of the CNDR complements that of the IOA by focusing on multidisciplinary clinical and basic research to increase understanding of the causes and mechanisms leading to brain dysfunction and degeneration in $\mathrm{AD}$, Parkinson's disease (PD), frontotemporal dementia (FTD), amyotrophic lateral sclerosis (ALS) and related disorders that occur increasingly with advancing age. CNDR promotes a number of important research initiatives such as the development of new and effective therapies and finding a cure for devastating aging-related neu- rodegenerative diseases through a number of mechanisms.

For example, CNDR is the home of the Administrative and Neuropathology Cores of the Alzheimer's Disease Core Center (ADCC; http://www.pennadc.org), which is one of 32 NIA-funded Alzheimer's Disease Centers (ADCs) in the United States [12]. Working with CNDR, the PENN ADCC has contributed to a dramatic expansion in basic and clinical research on $\mathrm{AD}$ and related disorders at PENN over the past 18 years by providing leadership, education and core support to enhance and stimulate investigations into the etiology, pathogenesis, diagnosis, treatment and prevention of these neurodegenerative diseases. The ADCC also funds Pilot Grants and it does so in partnership with the IOA and the Institute of Medicine and Engineering, which is led by Dr. Peter F. Davies. Commensurate with this growth, PENN is recognized as an international leader in research on $\mathrm{AD}$ and related disorders.

The mission of the PENN ADCC complements that of IOA and CNDR as it focuses on increasing understanding of and research on $\mathrm{AD}$ and related disorders at and beyond PENN, fostering interactions between this ADCC and other ADCs and/or institutions, interacting with the National Alzheimer's Coordinating Center (NACC), participating in NACC-sponsored ADC collaborative studies, and responding to NIA initiatives on AD and related disorders [12]. The Clinical Core of the PENN ADCC is located in the PENN Memory Center in close proximity to IOA offices in the PENN Ralston House. This ADCC Core is led by Steve Arnold, Associate Director of the ADCC, and the Clinical Core recruits, assesses and monitors $\mathrm{AD}$ and control subjects, including women and minorities. There also is a Latino Clinic that focuses on recruiting urban Latinos into the ADCC dementia and control study cohorts. The PENN Memory Center, which is led by Christopher Clark, works in close partnership with the ADCC and is dedicated to improving the health, well-being and quality of life of patients and their caregivers. Thus, the PENN Memory Center offers expert comprehensive diagnostic evaluation and a multidisciplinary team approach that provides good medical management, education and social support. As the home of the ADCC's Clinical Core, the Memory Center is responsible for carefully collecting data on the course of $\mathrm{AD}$ and related diseases in patients and providing an environment for the conduct of clinical research to improve the standard of care. Research ranges from the development of new diagnostic methods to the evaluation of new treatments. 
The other 2 key core components of the ADCC are the Data Management/Biostatistics Core led by Sharon Xie, and the Education and Information Transfer Core (EITC) led by Jason Karlawish. Both of these Cores are located in the PENN Ralston House adjacent to IOA offices. The ADCC Data Management/Biostatistics Core plays an important role in providing biostatistical support for studies conducted by ADCC investigators and their collaborators as well as in data management, which includes sharing PENN ADCC data sets with the other investigators through regularly scheduled data downloads to NACC. Notably, the EITC is a unique feature of ADCs that plays a critical role in educating professionals and the public about $\mathrm{AD}$ and related dementias. This is critical for increasing the participation of patients and controls in $\mathrm{AD}$ research. Moreover, the PENN EITC has taken the educational mission to a new level of sophistication by developing educational videos on $\mathrm{AD}$ and healthy brain aging for the public with the support of the MetLife Foundation. Further, Jason Karlawish has made the participation of cognitively impaired subjects in research a focus of his own studies, and his article in this special issue summarizes recent findings on the decision-making capacity of individuals who are cognitively impaired. This line of investigation is novel and significant because it could facilitate efforts to develop ways to measure the benefits of interventions to enhance cognition, improve our understanding of the staging of dementia and improve communication among patients, clinicians and families.

PENN also benefits from an excellent Division of Geriatric Medicine that is recognized for its outstanding clinical care program, as well as an exceptional Geriatric Medicine training program, which includes several fellowship opportunities. The division is led by Jerry Johnson, and it is dedicated to: enhancing the health of older adults by establishing models of interdisciplinary clinical care that span the array of sites in which elderly receive care; training physicians to provide excellent clinical care of older adults with an emphasis on enhancing functional status, quality of life and survival; conducting and facilitating research on issues of premier importance to the elderly; sponsoring community-based education and demonstration projects. The division is located in the PENN Ralston House in close proximity to the IOA and shares clinic space with the PENN Memory Center and the ADCC. Geriatric Psychiatry, led by Steven Arnold, also is located in PENN Ralston House. Under the new leadership of Steven Arnold, Geriatric Psychiatry will develop innovative research programs that enhance and strengthen partnerships between PENN research programs on aging-related neurodegenerative and neuropsychiatric diseases.

The most recent addition to PENN research programs on aging-related neurodegenerative diseases is a new $\mathrm{Na}$ tional Institute of Neurological Disorders and Stroke (NINDS) Morris K. Udall Parkinson's Disease Center of Excellence to study the molecular mechanisms that underlie the movement and dementia aspects of PD, as well as the care and treatment of patients and training of physicians. PD is one of the most common neurodegenerative diseases, second only to AD in the number of people affected. Estimates suggest that approximately 800,000 Americans have PD and this Udall Parkinson's Center will enable PENN to better combine achievements in clinical care for PD patients with basic science studies of PD and related disorders. The theme of the Udall Center is cognitive impairment, a very much neglected aspect of PD. John Trojanowski leads the Center's overall operations and conducts neuropathology research, while Howard Hurtig investigates potential markers of PD-related neurodegeneration and leads educational efforts for physicians and the lay community. Andrew Siderowf and Murray Grossman each lead projects that will define the nature of cognitive impairments in $\mathrm{PD}$, while Virginia Lee and Benoit Giasson each lead projects that study the nature of these impairments in mouse models and Sharon Xie oversees data management and biostatistics for the center. This Udall Center builds on 20 years of basic research on neurodegenerative diseases at PENN that enables psychiatrists, neurologists, geriatricians, pathologists, neuroscientists and biostatisticians to better interact under one virtual roof. Notably, PENN joins 13 other existing centers in this NINDS Udall Center network, but PENN is one of only 9 institutions that have both an NINDS-funded Udall Center and an NIA-funded Alzheimer Center.

Significantly, this new Udall Center partners with the PENN ADCC and it also takes advantage of outstanding clinical programs on $\mathrm{PD}$ and related movement disorders at PENN. For example, these disorders are the major clinical focus of the Parkinson's Disease and Movement Disorder Center (PD\&MDC) of the PENN Neurological Institute at the Pennsylvania Hospital and the Hospital of the University of Pennsylvania. Indeed, the PD\&MDC, which was founded in 1982 and is led by Matt Stern and Howard Hurtig, has grown over the past 25 years to become the largest facility of its kind in the Delaware Valley (encompassing Pennsylvania, New Jersey and Delaware) and a National Parkinson Foundation designated Center 
of Excellence. Moreover, the PD\&MDC is closely allied with the Parkinson's Disease Research, Education and Clinical Center (PADRECC) at the Philadelphia Veterans Hospital. This PADRECC, which is led by Matt Stern and John Duda, draws patients from the veteran population of the entire Delaware Valley, making it a magnet clinical site for underserved minority patients. Exciting research on PD and related $\alpha$-synucleinopathies that reflect the powerful synergies between investigators in the Udall Center, the PD\&MDC and the PADRECC are summarized in the review here by Rachel Gross, Andrew Siderowf and Howard Hurtig, the one by Sarah Kranick and John Duda as well as the review by Benoit Giasson and Vivianna Van Deerlin.

\section{New Partnerships/Directions for PENN Neurodegenerative Disease Research}

To prevent or ameliorate aging-related neurodegenerative diseases as well as to promote healthy aging, PENN faculty seek to develop novel partnerships and to take their research in new directions. Examples of recently launched novel initiatives and partnerships include the establishment of the Marian S. Ware Alzheimer Program, as well as PD drug discovery programs funded by generous support from the Picower and Benaroya families. Another novel program is exemplified by the PENN Biomarker Core of the NIA-funded Alzheimer's Disease Neuroimaging Initiative (ADNI) that is designed to test imaging and biological markers for measuring the progression of mild cognitive impairment (MCI) and early $\mathrm{AD}$, as well as for distinguishing normal controls from subjects with MCI or AD. With respect to the Marian S. Ware Alzheimer Program, this was successfully launched with generous philanthropic support from the Ware family in January 2004 to comprehensively attack the problem of $\mathrm{AD}$. This unique multidisciplinary program includes 3 key components: (1) AD Drug Discovery, led by Virginia Lee and John Trojanowski; (2) AD Clinical Trial Design, led by Chris Clark and Jason Karlawish; (3) Continuity of AD Care, led by Mary Naylor of the PENN School of Nursing.

Academic drug discovery programs for neurodegenerative diseases have the potential to bridge the gap between drug target identification, validation and proof of concept studies to hasten efforts to bring new therapies out of laboratories into the clinic. However, the funding opportunities for these programs are limited and it is gratifying that philanthropic sources of support for them are becoming available. For example, CNDR has been able to launch PD drug discovery programs with support from the Picower and Benaroya families. While these programs are new, they already are beginning to generate new leads for $\mathrm{AD}$ and $\mathrm{PD}$ drug discovery, and these efforts will be accelerated by the recruitment of Kurt Brunden from biotechnology as Director of CNDR Drug Discovery [13-19]. Moreover, in his review for this special issue, Paul Taylor describes another novel direction for neurodegenerative disease drug discovery that involves manipulating autophagy to eliminate misfolded proteins, since the accumulation of misfolded proteins is a pathological hallmark of AD, PD, FTD, ALS and almost all other aging-related neurodegenerative disorders.

However, partnerships with pharmaceutical and biotechnology companies as well as other entities are also needed to make these efforts successful, and a novel example of this is the NIA-funded ADNI program to develop and standardize $\mathrm{AD}$ biomarkers, as described in an article here by Leslie Shaw. Another related and novel PENN partnership is led by Christopher Clark, who obtained a Commonwealth of Pennsylvania Department of Health Tobacco Settlement grant to establish a Center of Excellence for Research on Neurodegenerative Diseases at PENN that focuses on studies to identify biomarkers for dementia of diverse etiologies, as described in his article in this special issue.

While biomarkers are critical for the early diagnosis of neurodegenerative diseases and for the expeditious assessment of disease-modifying therapies, additional targets for drug discovery and novel model systems are needed to rapidly screen compound libraries for new drug targets. Thus, there is considerable excitement at and beyond PENN about the discovery of a new disease protein known as TDP-43 that provides a molecular link between ALS and FTD [20,21]. These seemingly distinct disorders often co-occur for reasons that have not been clear, and Lauren Elman, Leo McCluskey and Murray Grossman provide a review here of evidence suggesting that FTD and ALS may be part of a spectrum of a single disorder linked to misfolding and aggregation of TDP43. This article is complemented by a related review written by Linda Kwong, Kunihiro Uryu, John Trojanowski and Virginia Lee that summarizes advances in understanding the pathobiology of TDP-43 proteinopathies and why they are distinct from other neurodegenerative disorders, most of which are characterized by brain amyloidosis. Efforts to develop powerful, cost-effective, rapid and informative model systems for studies of disease mechanisms underlying neurodegeneration as well as 
drug screening systems are reviewed in 2 separate articles written by Aaron Gitler and James Shorter. Notably, both of these recently recruited faculty were attracted to PENN because of the depth, breadth and diverse strengths of neurodegenerative disease research at PENN.

\section{Concluding Remarks}

As the mechanisms underlying aging-related neurodegenerative disorders such as AD, PD, ALS and FTD come into sharper focus, the pieces of the puzzle that must be solved to understand these disorders and develop better ways to diagnose and treat them are coming together at PENN (fig. 1). This is a direct result of the collegiality and team spirit of the cadre of researchers who have made conquering neurodegenerative diseases the major goal of their career. While Benjamin Franklin may not have foreseen the growing public health threat that aging-related neurodegenerative diseases signify now for the Nation he played a key role in establishing, or for the world as he knew it, we think it is likely he would consider the research summarized here in keeping with his concept of the college he proposed that has become the University of Pennsylvania.

\section{Acknowledgements}

We are indebted to the patients and their caregivers who have facilitated the study of neurodegenerative diseases. J.Q.T. is the William Maul Measey-Truman G. Schnabel, Jr. Professor of Geriatric Medicine and Gerontology. Support for the research summarized here comes from the NIH (AG09215, AG10124, AG11542, AG14382, AG14449, AG17586, NS044233), the MetLife Foundation and the Ware, Picower and Benaroya families. Mary Leonard is thanked for her expert help with the figure.

\section{References}

1 Meyer J: Age: 2000, Census Bureau Brief, $\mathrm{C} 2 \mathrm{KBR} / 01-12$. Washington, US Census $\mathrm{Bu}-$ reau, 2001.

2 Hetzel L, Smith A: The 65 years and over population: 2000, Census Bureau Brief, C2KBR/01-10. Washington, US Census Bureau, 2001.

3 Older Americans 2004: Key indicators of well-being. Federal Interagency Forum on Aging-Related Statistics. Washington, US Government Printing Office, 2004.

4 Rowe JW, Kahn, RL: Successful Aging. New York, Pantheon Books, 1998.

5 Manton KG, Gu X, Lamb VL: Changes in chronic disability from 1982 to $2004 / 2005$ as measured by long term changes in function and health in the U.S. elderly population. Proc Natl Acad Sci USA 2006;103:1837418379.

-6 Hebert LE, Scherr PA, Bienias JL Bennett DA, Evans DA: Alzheimer disease in the US population: prevalence estimates using the 2000 census. Arch Neurol 2003;60:11191122 .

7 The Lewin Group: Saving lives, saving money: dividends for Americans investing in Alzheimer research. Chicago, Alzheimer's Association, 2004.

-8 Brookmeyer R, Gray S, Kawas C: Projections of Alzheimer's disease in the United States and the public health impact of delaying disease onset. Am J Public Health 1998;88: 1337-1342.
9 Cogan JF, Mitchell OS: Perspectives from the President's Commission on Social Security Reform. J Econ Perspect 2003;7:149-172.

10 Jedrziewski MK, Lee VM-Y, Trojanowski JQ: Lowering the risk of Alzheimer's disease: evidence-based practices emerge from new research. Alzheimers Dement 2005;1:152160.

11 Jedrziewski MK, Lee VM-Y, Trojanowski JQ: Physical activity and cognitive health. Alzheimers Dement 2007;3:98-108.

12 Hodes RJ: Public funding for Alzheimer disease research in the United States. Nat Med 2006;12:770-773.

$\checkmark 13$ Ballatore C, Hyde E, Deicher R, Lee VM-Y, Trojanowski JQ, Huryn D, Smith AB III: Paclitaxel C10 carbamates: potential candidates for the treatment of neurodegenerative tauopathies. Bioorg Med Chem Lett 2007; 17: 3642-3646.

14 Crowe A, Ballatore C, Hyde E, Trojanowski JQ, Lee VM-Y: High throughput screening for small molecule inhibitors of heparin-induced tau fibril formation. Biomed Biophys Res Comm 2007;358:1-6.

15 Lee VM-Y, Trojanowski JQ: Mechanisms of Parkinson's disease linked to pathological $\alpha$ synuclein: new targets for drug discovery. Neuron 2006;52:33-38.

16 Skovronsky DM, Lee VM-Y, Trojanowski JQ: Neurodegenerative diseases: new concepts of pathogenesis and their therapeutic implications. Annu Rev Pathol Mech Dis 2006; 1: 151-170.
17 Trojanowski JQ, Duff K, Fillit H, Koroshetz W, Kuret J, Murphy D, Refolo L: New directions for frontotemporal dementia drug discovery. Alzheimers Dement 2007; in press.

18 Yoshiyama Y, Higuchi M, Zhang B, Huang S-M, Iwata N, Saido TC, Maeda J, Suhara T, Trojanowski JQ, Lee VM-Y: Synapse loss and microglial activation precede tangles in a P301S tauopathy mouse model. Neuron 2007;53:337-351.

19 Zhang B, Maiti A, Shively S, Lakhani F, McDonald-Jones G, Bruce J, Lee EB, Xie SX, Joyce S, Li C, Toleikis PM, Lee VM-Y, Trojanowski JQ: Microtubule binding drugs offset tau sequestration by stabilizing microtubules and reversing fast axonal transport deficits in a murine neurodegenerative tauopathy model. Proc Natl Acad Sci USA 2005;102:227-231.

-20 Kwong K, Neuman M, Samapathu D, Lee VM-Y, Trojanowski JQ: TDP-43 proteinopathy: the neuropathology underlying major forms of sporadic and hereditary frontotemporal lobar degeneration and motor neuron disease. Acta Neuropath 2007;114:63-70.

21 Neumann M, Sampathu DM, Kwong LK, Traux A, Miscenyi M, Chou TT, Bruce J, Schuck T, Grossman M, Clark C, McKlusky L, Miller BL, Masliah E, Mackenzie IR, Feldman H, Feiden W, Kretzschmar HA, Trojanowski JQ, Lee VM-Y: Ubiquitinated TDP43 in frontotemporal lobar degeneration and amyotrophic lateral sclerosis. Science 2006; 314:130-133. 